\title{
Microscopy \\ Characterization of U-Mo- Bearing Mini-Plates \\ Fabricated by Hot Isostatic Pressing (HIPping) With a Long Thermal Cycle
}

Jan-Fong Jue

July 2007

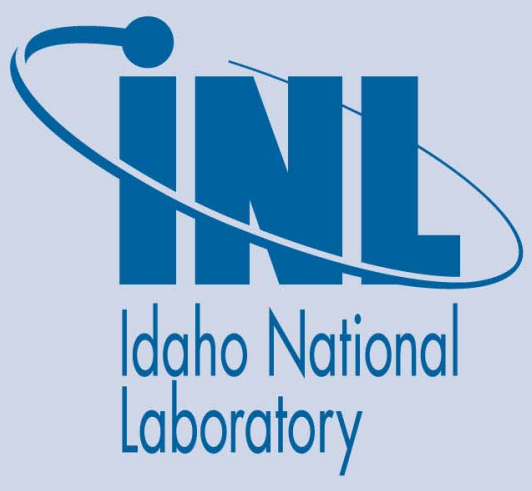

The INL is a U.S. Department of Energy National Laboratory operated by Battelle Energy Alliance 


\section{Microscopy Characterization of U-Mo-Bearing Mini- Plates Fabricated by Hot Isostatic Pressing (HIPping) With a Long Thermal Cycle}

Jan-Fong Jue

July 2007

Idaho National Laboratory

Idaho Falls, Idaho 83415

Prepared for the

U.S. Department of Energy

Office of Nuclear Energy

Under DOE Idaho Operations Office

Contract DE-AC07-05ID14517 


\section{DISCLAIMER}

This information was prepared as an account of work sponsored by an agency of the U.S. Government. Neither the U.S. Government nor any agency thereof, nor any of their employees, makes any warranty, expressed or implied, or assumes any legal liability or responsibility for the accuracy, completeness, or usefulness, of any information, apparatus, product, or process disclosed, or represents that its use would not infringe privately owned rights. References herein to any specific commercial product, process, or service by trade name, trade mark, manufacturer, or otherwise, does not necessarily constitute or imply its endorsement, recommendation, or favoring by the U.S. Government or any agency thereof. The views and opinions of authors expressed herein do not necessarily state or reflect those of the U.S. Government or any agency thereof. 


\begin{abstract}
The Reduced Enrichment for Research and Test Reactors Program has formed a Production Development Team to coordinate fabrication efforts to produce the fuel elements for the qualifying irradiation tests. These fuel elements will be fabricated in production facilities. Fabrication development data will be shared with all participants on the Development Team. The Idaho National Laboratory has been developing a method of cladding using a Hot Isostatic Press. The operating parameters were varied to understand the impact of time, pressure, and temperature on the reaction between the fuel and the cladding. This report details some of the data produced to date.
\end{abstract}




\section{CONTENTS}

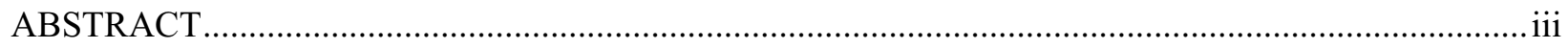

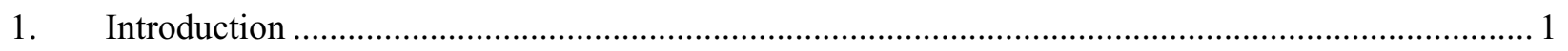

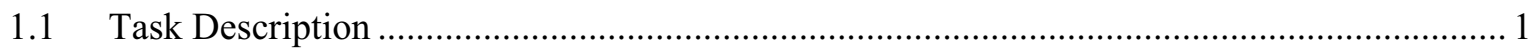

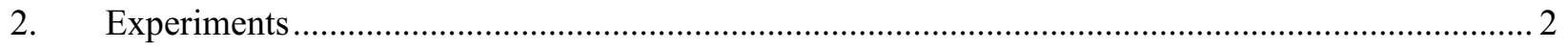

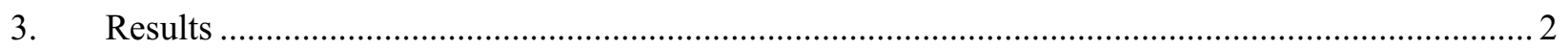

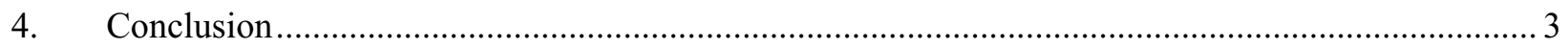

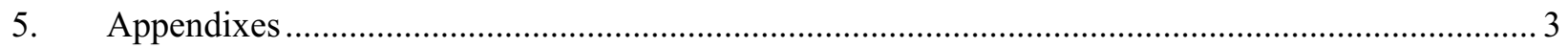

\section{FIGURES}

1. A UT-debond scan picture of a mini-plate containing a U-10Mo fuel foil.......................................... 4

2. A low-magnification SEM micrograph shows the cross-section of a mini-plate containing a

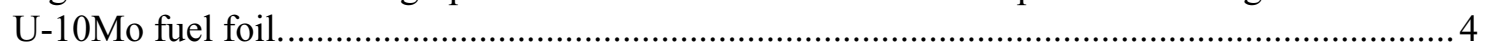

3. A SEM micrograph shows a very thin fuel/cladding reaction layer between the 6061-A1

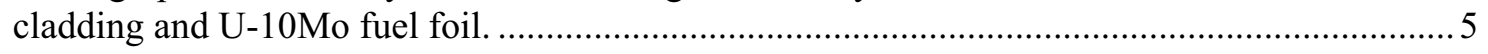

4. A UT-debond scan picture of a mini-plate containing a U-7Mo fuel foil.............................................5

5. A low-magnification SEM micrograph shows the 6061-Al cladding, Nb diffusion barrier, U-7Mo fuel foil, and the fuel/cladding reaction zone...................................................... 6

6. A SEM microgragh shows the extensive reaction between the U-7Mo fuel foil and 6061-Al

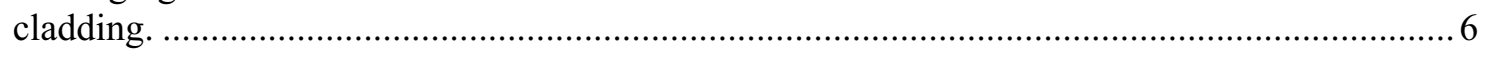

7. An optical micrograph shows the bond line between the 6061 -Al claddings. .................................... 7 


\section{Microscopy Characterization of U-Mo-Bearing Mini-Plates Fabricated by Hot Isostatic Pressing (HIPping) with a Long Thermal Cycle}

\section{Introduction}

In response to increasing congressional and public concern about the potential diversion of highly-enriched uranium (HEU) for use in nuclear weapons, the DOE initiated the Reduced Enrichment for Research and Test Reactors (RERTR) Program in August 1978.

The mission of the RERTR Program is to develop the technology needed to reduce, and eventually eliminate, world-wide use of HEU in civilian applications. In particular, the RERTR Program goal is to develop the technical means needed to use low-enriched uranium (LEU) fuel instead of HEU in research and test reactors, and to do so without significant penalties in experiment performance, economics, or safety aspects of the reactors.

The RERTR Program at the Idaho National Laboratory (INL) is composed of four major elements: 1) Advanced Fuel Development, 2) Fuel Supply for Core Conversion, 3) Domestic Reactor Conversions, and 4) Russian Program Support. The Advanced Fuel Development Effort develops fabrication techniques for research and test reactor fuels of very high uranium density and performs the tests needed to qualify them for use in reactors. The RERTR fuel development program works closely with fuel vendors to ensure a timely transition to new fuel technologies required for conversion.

The RERTR Program has formed the Production Development Team to coordinate fabrication efforts to produce the fuel elements for the qualifying irradiation tests. These fuel elements will be fabricated in production facilities. Fabrication development data will be shared with all participants on the development team. The INL has been developing a method of cladding using a Hot Isostatic Press (HIP). The operating parameters were varied to understand the impact of time, pressure, and temperature on the reaction between the fuel and the cladding. This report details some of the data produced to date.

\subsection{Task Description}

The INL examined the effect of long heating and cooling times on the reaction layer between the fuel and the cladding. Since May 2006, more than twenty HIP runs have been performed at the INL. The first activity was to decrease the HIP processing time and temperature from an operating temperature of $580^{\circ} \mathrm{C}$ for a duration of 180 minutes to a $560^{\circ} \mathrm{C}$ operating temperature for 90 minutes. The goal of this activity was to reduce the fuel/cladding reaction. However, to fabricate full-size fuel plates, the larger HIP at BWX Technologies, Inc. (BWXT) is required. Due to the long thermal cycle used in the full-size HIP at the BWXT, a HIP run with a slower heating/cooling rate was conducted at INL to better simulate the processing condition that will be used for the full-size fuel plate fabrication. The focus of this study was to find out the effect of the long thermal cycle on the extent of fuel/cladding reaction.

The mini-plates used in this experiment were loaded into a Hip can. Six different kinds of materials were used in the Hip can:

- $\quad$ Strongback

- Graphite foil

- 6061-Aluminum (Al) cladding (with and without a pocket)

- Diffusion barrier foil (Niobium (Nb) in this HIP run) 
- Uranium-molybdenum fuel foil (U-7Mo and U-10Mo in this HIP run)

- Stainless steel foil (surrogate foil, used as a control).

The stacking sequence was:

(i) Graphite foil

(ii) Strongback

(iii) Graphite foil

(iv) 6061-Al cladding with a pocket

(v) U-Mo foil/stainless steel foil

(vi) Diffusion barrier foil (if any)

(vii) 6061-Al cladding without a pocket.

The same process was repeated five more times; finally, a strongback and a graphite foil were added to the top of the stack. After stacking, the Hip can was welded in an argon (Ar) atmosphere glovebox followed by a helium leak check (leak rate needs to be less than $10^{-7} \mathrm{cc} / \mathrm{second}$ to pass). Then, the Hip can was baked out at $315^{\circ} \mathrm{C}$ for three hours under vacuum, cooled to room temperature, seal welded, and loaded into the HIP vessel. Due to the size of the HIP vessel, only one Hip can was processed at a time and each Hip can produced six mini-plates.

\section{Experiments}

Uranium-molybdenum (U-Mo) monolithic fuel-bearing mini-plates were fabricated by Hot Isostatic Pressing (HIPping) at $580^{\circ} \mathrm{C} / 15,000$ psi for 30 minutes. An initial pressure of 800 psi was applied to the HIP vessel at room temperature. At $400^{\circ} \mathrm{C}$, the pressure was gradually increased so that the vessel pressure reached $15,000 \mathrm{psi}$ at $580^{\circ} \mathrm{C}$. The heating/cooling rate was $72.5^{\circ} \mathrm{C}$ per hour instead of the standard heating/cooling rate of $290^{\circ} \mathrm{C}$ per hour. The total time above $560^{\circ} \mathrm{C}$ for this HIP run was 63 minutes. The mini-plates with U-7Mo or U-10Mo monolithic fuel were sectioned and rough-polished to a 1200-grit sandpaper surface-finish. These samples were then subjected to microstructure characterization, using optical and scanning electron microscopy (SEM).

\section{Results}

Figure 1 in Appendix A, "Micrographs," is an ultrasonic (UT)-scan picture of a U-10Mo-bearing mini-plate. No debonding was found in this mini-plate. Figure 2 is a SEM micrograph of the cross-section of the U-10Mo mini-plate. Extensive reaction between the 6061-Al cladding and U-10Mo fuel foil was not observed despite the long thermal cycle. As shown in Figure 3, the thickness of the reaction layer between the U-10Mo fuel and 6061-Al cladding is only $1-2 \mu \mathrm{m}$. This result indicates that the long processing time during HIPping did not cause extensive fuel/cladding reaction for mini-plates containing a U-10Mo fuel foil. 
Figure 4 is a UT-scan picture of a U-7Mo-bearing mini-plate. No debonding was observed in this mini-plate. Figure 5 is a low-magnification SEM micrograph of the cross-section of the mini-plate. Extensive reaction between the U-10Mo fuel foil and 6061-Al cladding can be seen. The crack in the reaction zone might take place while sectioning the mini-plate for microscopy characterization. As shown in Figure 6, the thickness of the reaction zone between the U-7Mo fuel foil and 6061-Al cladding is more than $200 \mu \mathrm{m}$. The reaction zone exhibits at least two uranium-bearing layers with distinct contrast. Also shown in Figure 6, is that a diffusion barrier $(\mathrm{Nb})$ on one side of the U-7Mo fuel foil effectively eliminates the fuel/cladding reaction. Developing a method to apply a thin diffusion barrier to the fuel foil is crucial for the fabrication of U-7Mo-bearing fuel plates by HIPping.

Figure 7 is an optical micrograph of the 6061-Al cladding. Note that the grain size of the 6061-Al cladding is about $20 \square \mathrm{m}$. This result indicates that the extensive grain growth of the 6061-Al cladding is not a concern for the long thermal cycle used in this HIP run.

\section{Conclusion}

Based on the information obtained from this HIP run, a couple of conclusions can be made:

(1) To fabricate U-10Mo-bearing fuel plates by HIPping with a long heating/cooling cycle will not result in extensive fuel/cladding reaction. A diffusion barrier is not required.

(2) To fabricate fuel plates with U-7Mo fuel foil by HIPping with a long heating /cooling cycle will result in extensive fuel/cladding reaction. A diffusion barrier is required to prevent such a fuel/cladding reaction.

\section{Appendixes}

Appendix A, Micrographs 


\section{Appendix A}

\section{Micrographs}

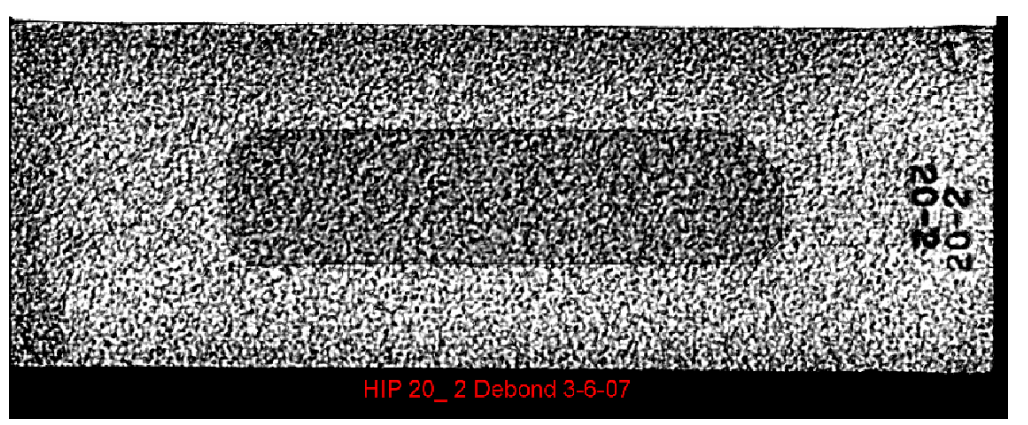

Figure 1. A UT-debond scan picture of a mini-plate containing a U-10Mo fuel foil.

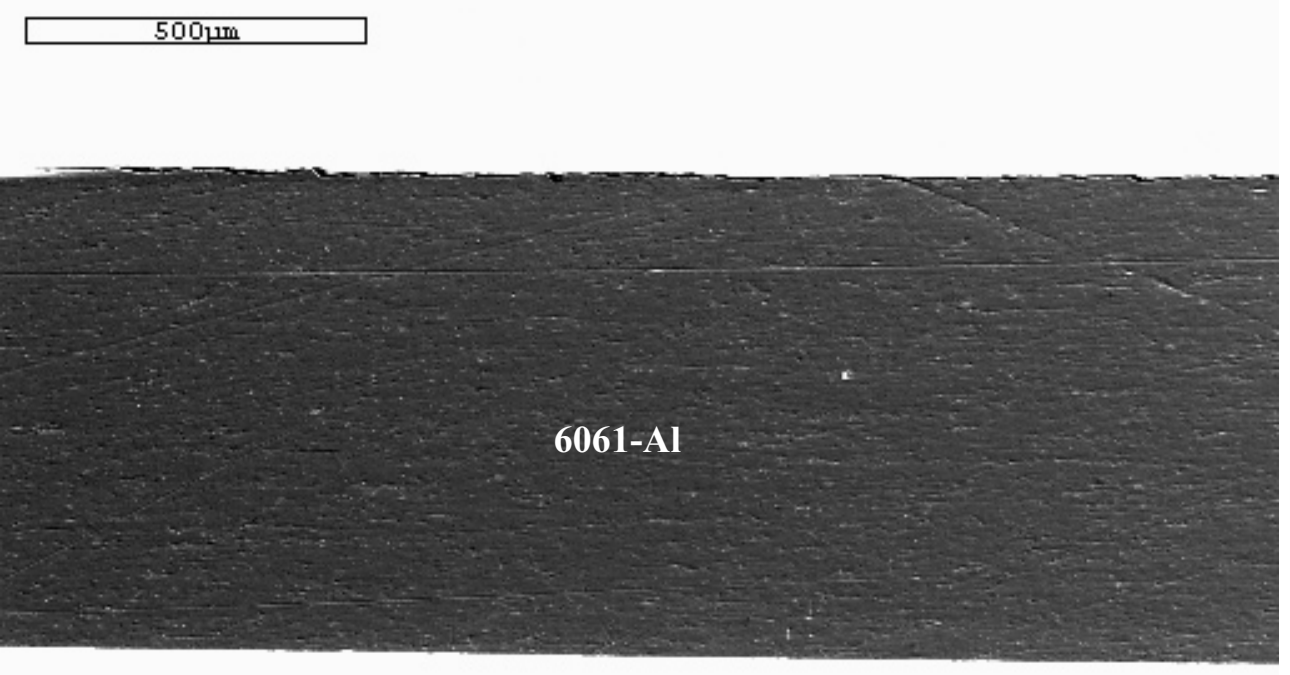

U-10Mo

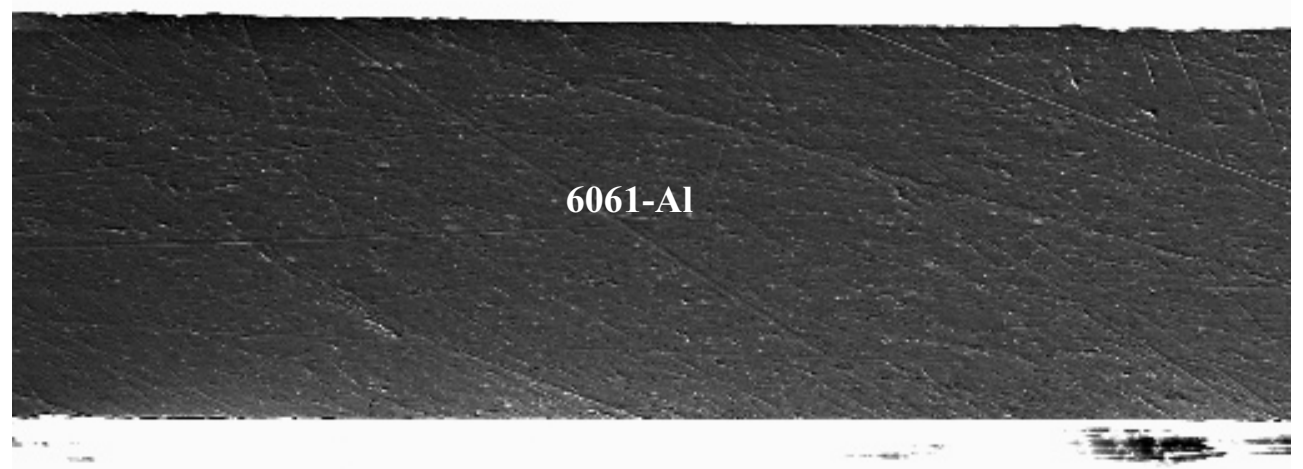

Figure 2. A low-magnification SEM micrograph shows the cross-section of a mini-plate containing a U-10Mo fuel foil. 


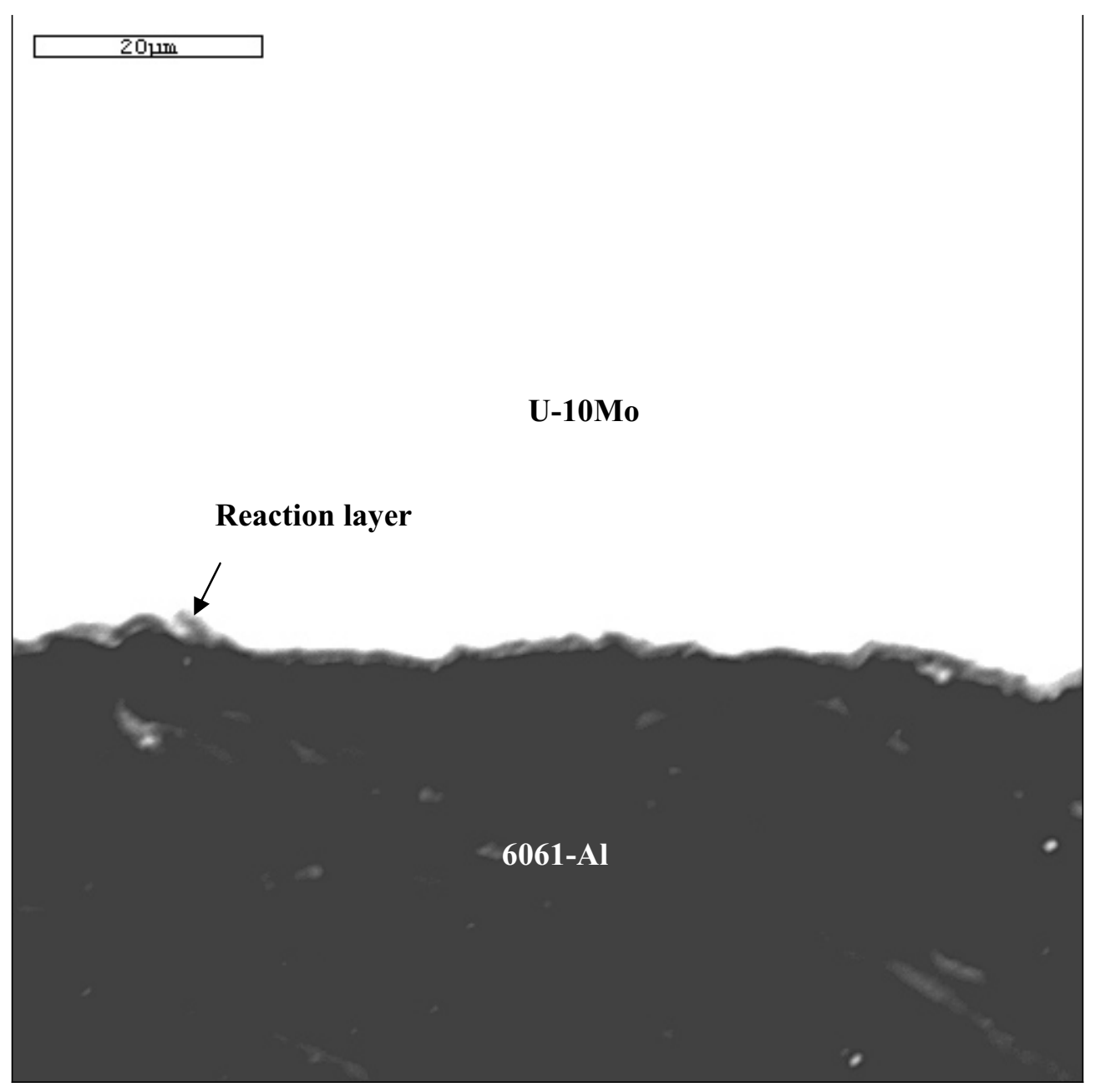

Figure 3. A SEM micrograph shows a very thin fuel/cladding reaction layer between the 6061-Al cladding and U-10Mo fuel foil.

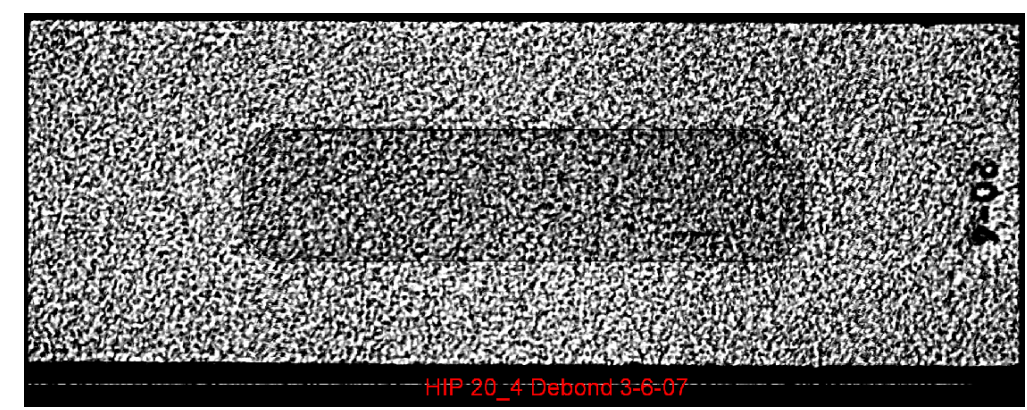

Figure 4. A UT-debond scan picture of a mini-plate containing a U-7Mo fuel foil. 


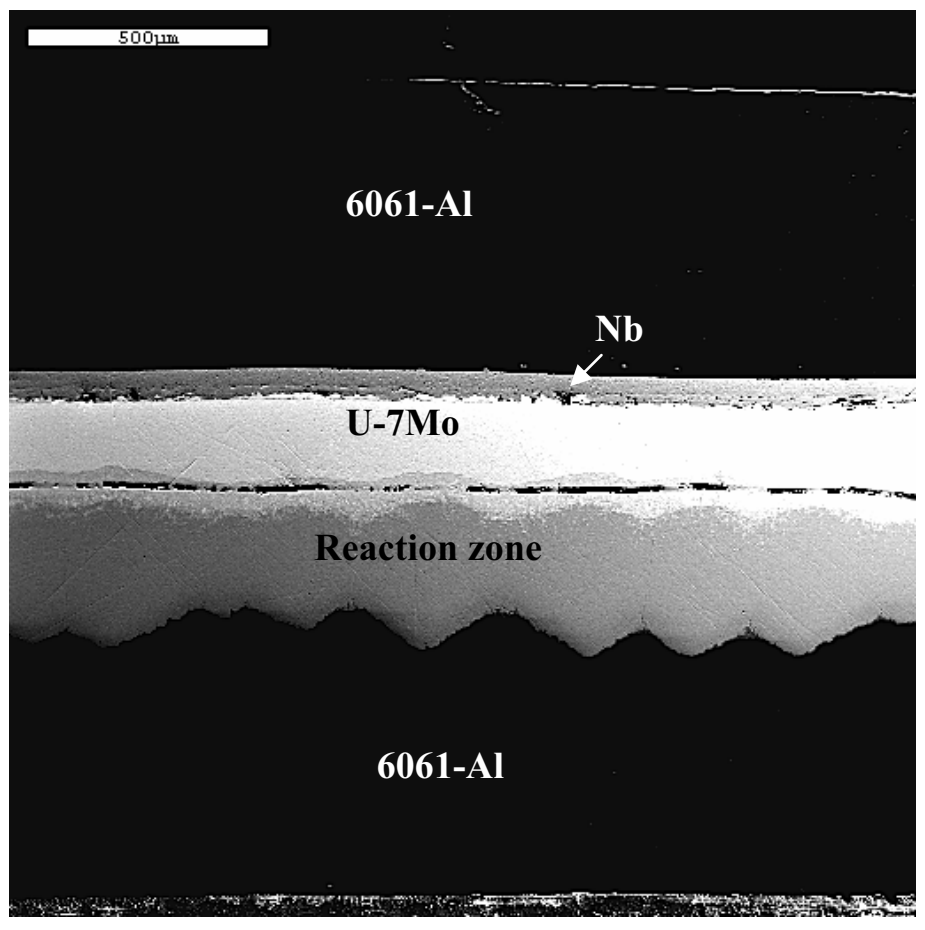

Figure 5. A low-magnification SEM micrograph shows the 6061-Al cladding, $\mathrm{Nb}$ diffusion barrier, U-7Mo fuel foil, and the fuel/cladding reaction zone.

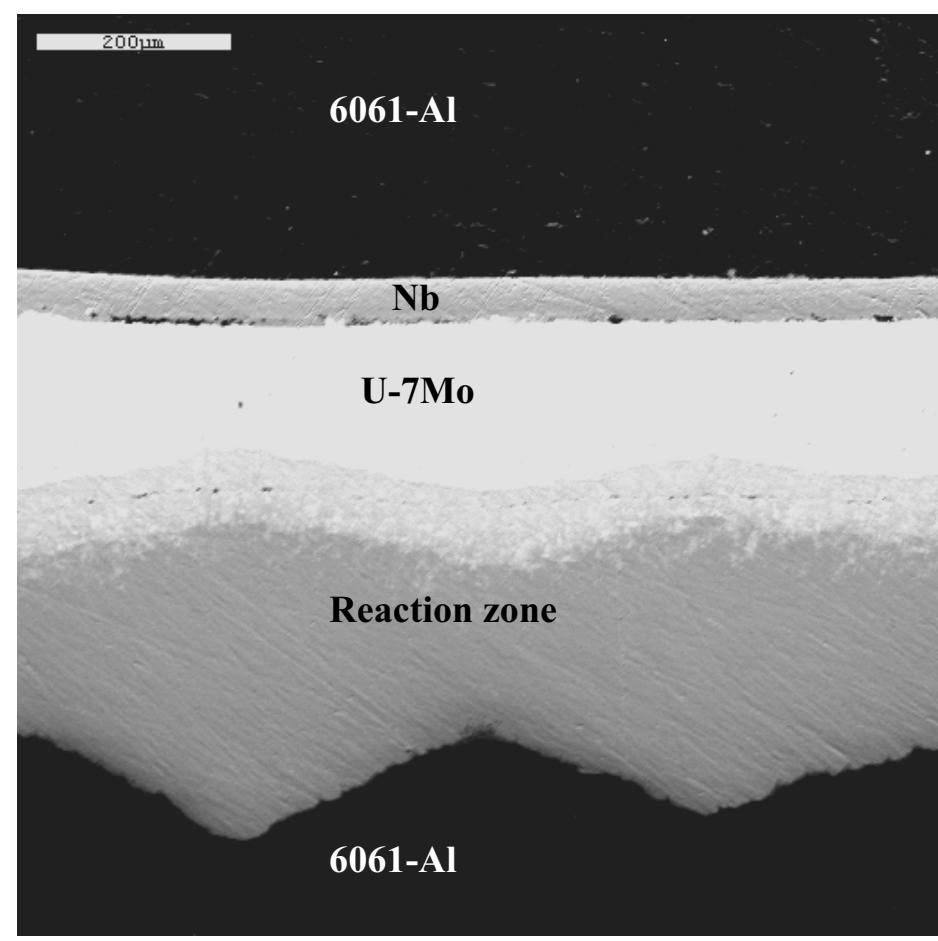

Figure 6. A SEM microgragh shows the extensive reaction between the U-7Mo fuel foil and 6061-Al cladding. 


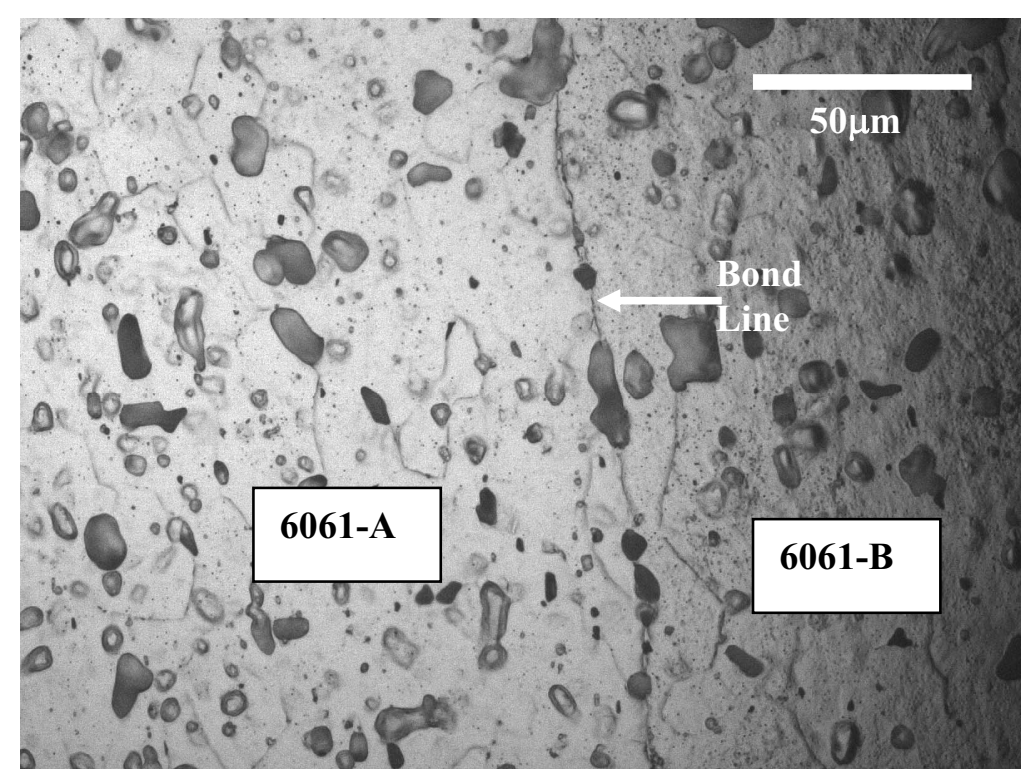

Figure 7. An optical micrograph shows the bond line between the 6061-Al claddings. 